\title{
Исследование поперечного скола структур методом комбинационного рассеяния света
}

\author{
(C) С.М. Планкина*, О.В. Вихрова ${ }^{+}$, Ю.А. Данилов* , Б.Н. Звонков ${ }^{+}$, \\ Н.Ю. Коннова*, А.В. Нежданов*, И.Ю. Пашенькин* \\ * Нижегородский государственный университет им. Н.И. Лобачевского, \\ 603950 Нижний Новгород, Россия \\ + Научно-исследовательский фризико-технический институт \\ Нижегородского государственного университета им. Н.И. Лобачевского, \\ 603950 Нижний Новгород, Россия \\ E-mail: plankina@phys.unn.ru
}

(Получена 27 апреля 2016 г. Принята к печати 10 мая 2016 г.)

Методом сканирующей конфокальной спектроскопии комбинационного рассеяния света исследована кристаллическая структура GaAs, облученного ионами $\mathrm{Mn}^{+}$с последующим импульсным лазерным отжигом. Сканирование поперечного скола образцов показало, что в результате лазерного отжига она полностью восстанавливается на всю глубину имплантации. Обнаружено рассеяние на связанной фонон-плазмонной моде, свидетельствующее об электрической активации примеси при дозах марганца выше $1 \cdot 10^{16} \mathrm{~cm}^{-2}$. На примере данных исследований продемонстрированы возможности метода сканирующей конфокальной спектроскопии комбинационного рассеяния света при исследовании поперечного скола структур, а на тестовом образце с $\delta$-слоем углерода установлено, что латеральное разрешение метода составляет 300 нм.

\section{1. Введение}

Метод конфокальной спектроскопии комбинационного рассеяния света (микро-КРС) является чрезвычайно информативным, и в то же время неразрушающим методом, не требующим специальной подготовки образцов. Однако в геометрии обратного рассеяния, когда волновые векторы падающего и рассеянного света нормальны к плоскости структуры, можно получить информацию только о приповерхностных слоях толщиной в несколько десятков нанометров. Поэтому для исследования многослойных структур все чаще используется, например, пространственное (по глубине эпитаксиального слоя) картографирование фононных спектров комбинационного рассеяния света (КРС) пошаговым перемещением фокуса от поверхности к границе с подложкой [1] или сканирование косого шлифа структуры [2,3]. На наш взгляд, первый способ затруднителен для интерпретации результатов из-за сложности привязки спектров к координате сканирования в силу зависимости фокусного расстояния от коэффициента поглощения [4]. Использование косого шлифа позволяет значительно увеличить разрешающую способность метода и получить интересные результаты, но при этом требуется специальная подготовка образцов. В ряде работ $[5,6]$ используется сканирование поперечного скола структур (с торца), и авторы считают, что латеральное разрешение при исследовании поперечного скола равно размеру лазерного пучка в фокусе. Такая конфигурация, на наш взгляд, очень интересна для исследования многослойных структур, так как позволяет получать информацию о пространственной однородности кристаллической структуры и распределении деформаций в слоях. При этом из-за неоднородного распределения лазерного излучения в пучке и в соответствии с критерием Рэлея латеральное разрешение должно быть субмикронным [7].

Цель данной работы заключалась в выяснении возможностей исследования методом конфокальной спектроскопии комбинационного рассеяния света поперечного скола структур на основе полупроводников $\mathrm{A}^{\mathrm{III}} \mathrm{B}^{\mathrm{V}}$.

\section{2. Методика эксперимента}

Были исследованы ионно-имплантированные образцы GaAs:Mn после наносекундного импульсного лазерного отжига. Методика наносекундного импульсного лазерного отжига перспективна для восстановления кристаллической структуры и активации примеси в сильно легированных ионно-облученных полупроводниках [8]. В качестве исходных использованы пластины $i$-GaAs (100), облученные ионами $\mathrm{Mn}^{+}$с энергией 50-200кэВ и дозами $\left(D_{\mathrm{Mn}}\right)$ в диапазоне $1 \cdot 10^{13}-5 \cdot 10^{16} \mathrm{~cm}^{-2}$. Глубина имплантации, рассчитанная с применением программы TRIM [9], для энергии ионов 200 кэВ составляет 300 нм. Импульсный лазерный отжиг выполнен в ИФМ РАН с помощью эксимерного лазера LPX-200 $(\mathrm{KrF})$ с длиной волны излучения 248 нм, длительностью импульса $\approx 30$ нс, плотностью энергии в импульсе до 500 мДж/см². Задачей исследования комбинационного рассеяния было выяснение влияния дозы введенного марганца и условий импульсного лазерного отжига на свойства облученных слоев GaAs:Mn.

В качестве тестовой для определения латерального разрешения метода была использована выращенная методом МОС-гидридной эпитаксии при атмосферном давлении гетероструктура с квантовой ямой $\operatorname{In}_{y} \mathrm{Ga}_{1-y}$ As и одиночным $\delta$-слоем углерода в буферном слое $\operatorname{In}_{x} \mathrm{Ga}_{1-x}$ As. 


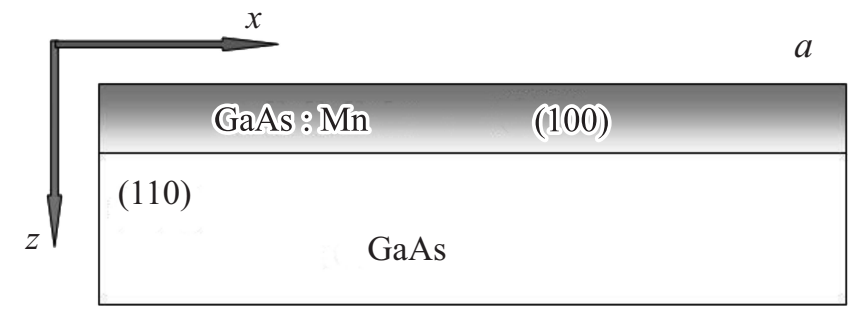

$b$

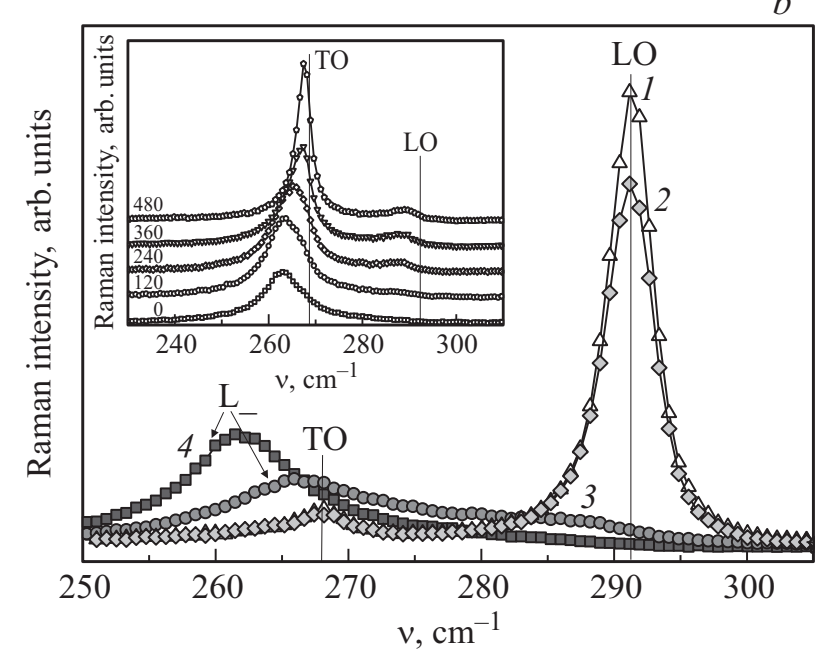

Рис. 1. $a-$ схема образца и две конфигурации геометрии обратного рассеяния. Сканирование поперечного скола образцов проходило в направлении $z . b-$ спектры КРС поверхности (100) лазерно-отожженных слоев GaAs:Mn с различной дозой имплантации, $\mathrm{cm}^{-2}: 1-1 \cdot 10^{13}, 2-1 \cdot 10^{14}, 3-1 \cdot 10^{16}$, $4-5 \cdot 10^{16}$. На вставке приведены спектры КРС от поперечного скола (110) образца с дозой $5 \cdot 10^{16} \mathrm{~cm}^{-2}$ на различном расстоянии от поверхности (указано рядом с кривыми, нм).

Исследования спектров КРС проводились на установке „ИНТЕГРА Спектра“ при комнатной температуре с использованием лазера с длиной волны 0.473 мкм. Излучение фокусировалось $100 \times$ объективом с апертурой $\mathrm{NA}=0.95$ в пятно диаметром $\sim 1$ мкм, мощность пучка составляла $\sim 0.5 \mathrm{MB}$. Спектры регистрировались в геометрии обратного рассеяния в двух конфигурациях (рис. $1, a)$ : от плоскости $(100)$ и от поперечного скола структуры по плоскости спайности (110) в режиме латерального сканирования. Сканирование проводилось по направлению [100] (обозначено как $z$ ), с шагом $20-40$ нм.

\section{3. Экспериментальные результаты и обсуждение}

Исследование спектров КРС от поверхности (100) образцов $\mathrm{GaAs}$, облученных ионами $\mathrm{Mn}$, показывает, что без лазерного отжига приповерхностная область является аморфной даже при небольших дозах имплантации. Лазерный отжиг приводит к восстановлению кристаллической структуры. Условие лазерного отжига, а именно изменение плотности энергии в импульсе от

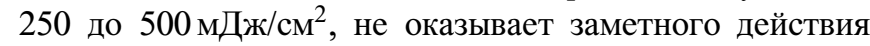
на свойства слоев GaAs:Mn. Гораздо большее влияние имеет доза введенного марганца. На рис. $1, b$ приведены спектры КРС от поверхности (100) образцов, облученных различными дозами Mn. В соответствии с правилами отбора в данной геометрии разрешенной является LO-мода, которая доминирует на спектрах образцов с дозой имплантации $1 \cdot 10^{13}$ и $1 \cdot 10^{14} \mathrm{~cm}^{-2}$ (кривые 1,2 ). Появление на этих спектрах запрещенной поперечной моды связано с конечностью входной апертуры спектрометра. Вид спектров свидетельствует о том, что в результате лазерного отжига происходит кристаллизация облученных слоев. С ростом дозы имплантации $\mathrm{Mn}$ до $1 \cdot 10^{16}$ и $5 \cdot 10^{16} \mathrm{~cm}^{-2}$ LO-мода исчезает, появляется связанная фонон-плазмонная мода (СФПМ, на рисунке обозначена как $\left.L_{-}\right)$, свидетельствующая об электрической активации примеси, возможной только при образовании твердого раствора GaMnAs. Вид спектров аналогичен полученным в работе [10]. По виду кривых 3 и 4 трудно сделать вывод о кристаллических свойствах слоев. Исследование поперечного скола структуры позволяет этот вопрос решить, так как правила отбора запрещают появление продольной моды и СФПМ от плоскости (110). На вставке приведены спектры, полученные от поперечного скола структуры с максимальной дозой имплантации $5 \cdot 10^{16} \mathrm{~cm}^{-2}$ на различном расстоянии от поверхности. Как видно из рисунка, на всех спектрах доминирует разрешенная в данной геометрии ТО-мода. Это свидетельствует о том, что в результате лазерного отжига происходит кристаллизация облученного слоя на всю глубину имплантации.

На рис. 2 приведена аппроксимация функцией Лоренца спектра КРС от поперечного скола (110) образца с дозой $5 \cdot 10^{16} \mathrm{~cm}^{-2}$ на расстоянии $z=300$ нм от поверхности. Видно, что в частотном диапазоне $263-267 \mathrm{~cm}^{-1}$

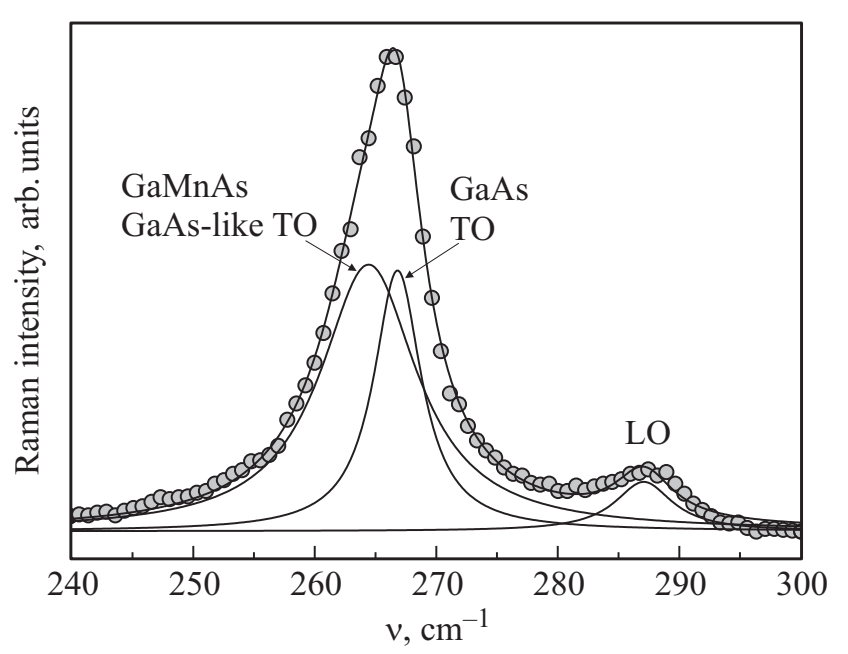

Рис. 2. Аппроксимация функцией Лоренца спектра КРС от поперечного скола (110) образца с дозой $5 \cdot 10^{16} \mathrm{~cm}^{-2}$ на расстоянии $z=300$ нм от поверхности. 
разрешаются две поперечные моды: от подложки GaAs и от образованного в результате имплантации и лазерного отжига слоя твердого раствора GaMnAs (GaAs-подобная ТО-мода). Продольные моды не разрешаются из-за меньшей интенсивности. Аппроксимация функцией Лоренца позволила построить зависимости отклонения частоты ТО-моды в облученном слое от значения $v_{0}=268.6 \mathrm{~cm}^{-1}$, характерного для GaAs, от координаты сканирования. На рис. 3 они приведены для образцов с максимально различающимися дозами имплантации. В образце с дозой имплантации $10^{13} \mathrm{~cm}^{-2}$ (кривая 1) сдвига ТО-моды не наблюдается. Интенсивность моды в направлении сканирования растет монотонно, полная ширина линии на полувысоте меньше $3 \mathrm{~cm}^{-1}$ и остается постоянной (здесь не приводятся). Иное поведение демонстрируют зависимости, полученные на образце с дозой имплантации $5 \cdot 10^{16} \mathrm{~cm}^{-2}$. Кривые 2 и 3 показывают сдвиг поперечных мод в слое GaMnAs и подложке соответственно. Область, где одновременно регистрируются обе моды, составляет 300 нм, что должно соответствовать латеральному разрешению метода сканирующей конфокальной спектроскопии комбинационного рассеяния света. Кривая 4 соответствует частотному положению суперпозиции этих мод. Интенсивность GaAs-подобной TO-моды изменяется немонотонно с максимумом при 180 нм (кривая 5), находящимся вблизи середины облученного слоя. Интенсивность ТО-моды GaAs (кривая 6) растет монотонно по мере приближения к подложке. Отклонение частотного положения поперечной моды у поверхности в низкочастотную сторону составляет $5.5 \mathrm{~cm}^{-1}$. Полная ширина поперечной моды GaAs на полувысоте увеличивается от $2.6 \mathrm{~cm}^{-1}$ в подложке до $4.8 \mathrm{~cm}^{-1}$ на границе с облученным слоем, GaAs-подобной TO-моды - от $3.2 \mathrm{~cm}^{-1}$ до $10.5 \mathrm{~cm}^{-1}$ в направлении к поверхности.

Частотное положение поперечной моды в образце с дозой имплантации $5 \cdot 10^{16} \mathrm{~cm}^{-2}$ определяется двумя факторами: содержанием марганца в твердом растворе GaMnAs (причем распределение марганца не является равномерным) и напряжениями, возникающими изза различий параметров решетки твердого раствора и GaAs. Оценка максимального содержания марганца по отклонению положения ТО-моды с использованием данных [10] без учета влияния напряжений дает значение $6 \%$. Параметр решетки GaMnAs с содержанием Mn 6\% $a=0.5674$ нм и рассогласование $\Delta a / a(\%)$ в соответствии с данными [11] составляет $0.32 \%$ относительно GaAs. Это приводит к возникновению напряжения сжатия в слое GaMnAs и сдвигу фононных мод в высокочастотную сторону. Таким образом, не учитывая напряжения при оценке состава твердого раствора, мы можем только занижать реальное значение содержания Мn в слое.

Считается, что латеральное разрешение при исследовании поперечного скола равно размеру лазерного пучка в фокусе [6], однако в соответствии с критерием Рэлея для $\lambda=0.473$ мкм оно должно составлять 300 нм [7].

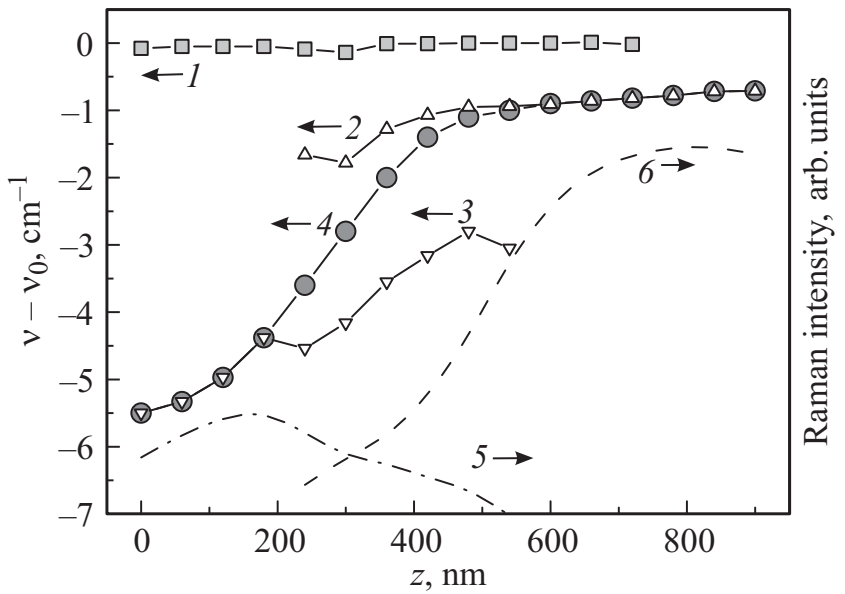

Рис. 3. Зависимость от координаты сканирования отклонения частоты поперечных мод от положения в $\mathrm{GaAs}(1-4)$ и их интенсивности $(5,6)$ в лазерно-отожженных образцах с дозой имплантации, $\mathrm{cm}^{-2}: 1-10^{13} ; 2-6-5 \cdot 10^{16}$. Поперечные моды: 2, 6 - ТО-мода подложки GaAs; 3, 5 - GaAs-подобная TO-мода слоя GaMnAs; 4 - суперпозиция TO-моды подложки GaAs и GaAs-подобной TO-моды слоя GaMnAs.

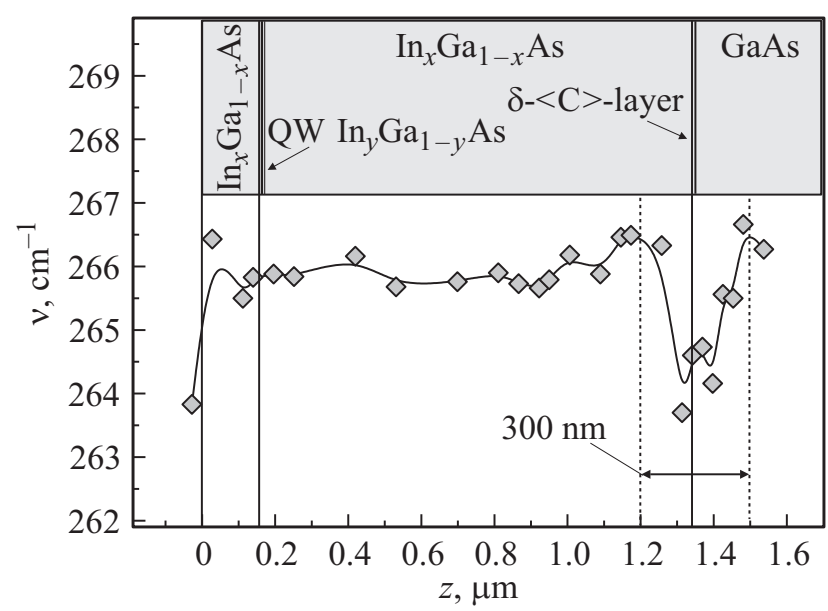

Рис. 4. Зависимость частотного положения GaAs-подобной ТО-моды твердого раствора $\operatorname{In}_{x} \mathrm{Ga}_{1-x}$ As от координаты сканирования в тестовой структуре с квантовой ямой $\operatorname{In}_{y} \mathrm{Ga}_{1-y} \mathrm{As}$ и $\delta$-слоем углерода. На вставке приведена схема структуры.

Для выяснения этого вопроса была использована тестовая структура, схема которой приведена на вставке к рис. 4. На спектрах КРС (здесь не приводятся), полученных на поперечном сколе структуры в пределах слоя $\operatorname{In}_{x} \mathrm{Ga}_{1-x} \mathrm{As}$, обнаруживается рассеяние на GaAs-подобных и InAs-подобных TO-фононах. Частотное положение и интенсивность фононных мод зависят от координаты сканирования. На рис. 4 приведена зависимость частотного положения наиболее интенсивной GaAs-подобной ТО-моды. Видно, что вблизи $\delta$-слоя углерода наблюдается заметный низкочастотный сдвиг, который связан с уменьшением параметра решетки и появлением локальных напряжений растяжения в ре- 
зультате замещения мышьяка углеродом [12]. Профиль изменения частоты является сверткой эффективности комбинационного рассеяния (являющейся функцией частоты $v$ и координаты $z$ ) и пространственного распределения интенсивности падающего лазерного пучка. $\delta$-слой размывается до $300 \mathrm{Hм}$, что фактически соответствует латеральному разрешению метода для длины волны лазерного излучения 0.473 мкм. В таком же диапазоне координат одновременно регистрируются ТО-мода от GaAs и GaAs-подобная TO-мода от слоя твердого раствора GaMnAs (рис. 3).

Квантовая яма $\operatorname{In}_{y} \mathrm{Ga}_{1-y} \mathrm{As} / \mathrm{In}_{x} \mathrm{Ga}_{1-x} \mathrm{As}$ на спектрах КРС тестовой структуры не обнаруживается не только из-за слабой интенсивности полезного сигнала от тонкого (10 нм) слоя, но и по причине действия двух факторов, влияющих на частотное положение GaAs-подобной и InAs-подобной фононных мод и компенсирующих друг друга. Напряжения сжатия в квантовой яме приводят к высокочастотному, а увеличение содержания In в квантовой яме по сравнению с буферным слоем - к низкочастотному сдвигу положения фононных мод.

\section{4. Заключение}

Продемонстрированы возможности конфокальной сканирующей спектроскопии комбинационного рассеяния при исследовании кристаллического качества сильно легированных в процессе имплантации и последующего импульсного лазерного отжига слоев GaAs:Mn. Аппроксимация спектров КРС от поперечного скола структуры выявила наличие двух поперечных мод: от подложки GaAs и GaAs-подобной TO-моды от легированного Mn слоя GaAs. Вместе с обнаружением рассеяния на связанной фонон-плазмонной моде это доказывает образование в результате имплантации и лазерного отжига твердого раствора GaMnAs. Оценка максимального содержания марганца в GaMnAs дает 6\%. Показано, что латеральное разрешение метода сканирующей конфокальной спектроскопии комбинационного рассеяния составляет $300 \mathrm{Hм}$.

Работа выполнена в рамках реализации государственного задания (проект № 8.1054.2014/К) Министерства образования и науки России, при поддержке РФФИ (гранты № 15-02-07824_a, 16-07-01102_a).

\section{Список литературы}

[1] В.В. Стрельчук, В.П. Кладько, Е.А. Авраменко, А.Ф. Коломыс, Н.В. Сафрюк, Р.В. Конакова, Б.С. Явич, М.Я. Валах, В.Ф. Мачулин, А.Е. Беляев. ФТП, 44, 1236 (2010).

[2] R.M.B. Agaiby, S.H. Olsen, P. Dobrosz, H. Coulson, S.J. Bull, A.G. O’Neill. J. Appl. Phys., 104 (1), 013507 (2008).

[3] R. Srnanek, J. Geurts, M. Lentze, G. Irmer, D. Donoval, P. Brdecka, P. Kordos, A. Förster, B. Sciana, D. Radziewicz, M. Tlaczala. Appl. Surf. Sci., 230 (1-4), 379 (2004).

[4] N.J. Everall. Appl. Spectroscopy, 54 (10), 1515 (2000).
[5] В.А. Володин. Письма ЖЭТФ, 89 (8), 483 (2009).

[6] В.А. Володин. ФТТ, 53, 377 (2011).

[7] Л. Новотный, Б. Хехт. Основы нанооптики (М., Физматлит, 2009).

[8] А.В. Двуреченский, Г.А. Качурин, Е.В. Нидаев, Л.С. Смирнов. Импульсный отжси полупроводниковых материалов (М., Наука, 1982).

[9] J.F. Ziegler. Nucl. Instrum. Meth. Phys. Res. B, 219/220, 1027 (2004).

[10] W. Limmer, M. Glunk, S. Mascheck, A. Koeder, D. Klarer, W. Schoch, K. Thonke, R. Sauer, A. Waag. Phys. Rev. B, 66, 205209 (2002).

[11] F. Matsukura, H. Ohno, T. Dietl. In: Handbook of Magnetic Materials, ed. K.H.J. Buschow (Elsevier, Amsterdam, 2002) v. 14 , p. $1-87$.

[12] Б.Н. Звонков, О.В. Вихрова, Ю.А. Данилов, Ю.Н. Дроздов, М.Н. Дроздов, И.Л. Калентьева, А.В. Кудрин. ФТП, 46, 1527 (2012).

Редактор А.Н. Смирнов

\section{Study of structures by Raman scattering spectroscopy on cleaved cross-sections}

S.M. Plankina*, O.V. Vikhrova+, Yu.A. Danilov*, B.N. Zvonkov ${ }^{+}$, N.Yu. Konnova*, A.V. Nezhdanov*, I.Yu. Pashenkin*

* Lobachevsky State University of Nizhny Novgorod, 603950 Nizhny Novgorod, Russia

+ Physicotechnical Research Institute of the Lobachevsky State University of Nizhny Novgorod, 603950 Nizhny Novgorod, Russia

Abstract Scanning confocal Raman spectroscopy was applied to study the cleaved cross-sections of semiconductor structures with layer fabricated by implantation of ions $\mathrm{Mn}^{+}$with subsequent pulsed laser annealing. We show how combination a backscattering geometry from a plane (100) and a lateral scanning of cleaved facets (110) allows us to demonstrate clearly that the implanted layers were crystallized in annealing process for all thickness. Using test structure with single $\delta\langle\mathrm{C}\rangle$-doped InGaAs layer we show that lateral resolution of the scanning micro-Raman spectroscopy is of $300 \mathrm{~nm}$. 